\title{
Defining Minimum Necessary Communication During Care Transitions for Patients on Antihyperglycemic Medication: Consensus of the Care Transitions Task Force of the IPRO Hypoglycemia Coalition
}

\author{
Medha N. Munshi · Sarah L. Sy · Hermes J. Florez · Elbert S. Huang · \\ Kasia J. Lipska · Anne Myrka (D) - Willy Marcos Valencia • \\ Joyce Yu • Darren M. Triller
}

Received: January 4, 2022 / Accepted: January 28, 2022 / Published online: February 28, 2022

(C) The Author(s) 2022

\section{ABSTRACT \\ Introduction: Antihyperglycemic agents are significant contributors to adverse drug events, responsible for emergency department visits, hospitalizations, and death. Nationally, the rate of serious hypoglycemic events associated with}

Medha N. Munshi, Hermes J. Florez, Elbert S. Huang, Kasia J. Lipska, Anne Myrka, Willy Valencia-Rodrigo, and Darren M. Triller contributed to the Task Force consensus process.

M. N. Munshi · H. J. Florez - E. S. Huang

K. J. Lipska · A. Myrka ( $₫)$. W. Marcos Valencia

D. M. Triller

IPRO Hypoglycemia Coalition, Care Transitions

Task Force Member, 20 Corporate Woods Blvd.,

Albany, NY 12211, USA

e-mail: amyrka@ipro.org

M. N. Munshi

Joslin Diabetes Center, Boston, MA, USA

M. N. Munshi

Division of Gerontology, Beth Israel Deaconess

Medical Center, Boston, MA, USA

M. N. Munshi

Harvard Medical School, Boston, MA, USA

S. L. Sy

Faculty of Medicine, University of British Columbia, Vancouver, Canada

\section{S. L. Sy}

Division of Geriatric Medicine, Vancouver General Hospital, Vancouver, Canada these agents remains high despite widespread efforts to improve drug safety. Transitions of care between healthcare settings can lead to communication challenges between care professionals and increase the risk of adverse drug events. System-based improvements are needed to assure the safe transitions for patients with diabetes who are on antihyperglycemic agents. The objective of this study was to develop a consensus list of requisite elements that should be communicated between care settings during

\section{H. J. Florez}

Public Health Sciences and Medicine, University of Miami Miller School of Medicine, Miami, FL, USA

H. J. Florez - W. Marcos Valencia

Geriatric Research, Education, and Clinical Center (GRECC), Miami Veteran Affairs Healthcare System, Miami, FL, USA

W. Marcos Valencia

Florida International University, Robert Stempel

College of Public Health, Miami, FL, USA

E. S. Huang

Center for Chronic Diseases Research and Policy, University of Chicago, Chicago, IL, USA

K. J. Lipska

Section of Endocrinology, Department of Internal Medicine, Yale School of Medicine, New Haven, CT, USA

A. Myrka - D. M. Triller

Island Peer Review Organization (IPRO), Albany, NY, USA 
transitions of patients who are prescribed antihyperglycemic agents.

Methods: The Island Peer Review Organization (IPRO) Hypoglycemia Coalition identified suboptimal transitions of care as a barrier to improving patient safety and quality of diabetes care. The Coalition formed a multidisciplinary Task Force with experts in the field of diabetes care. The Task Force created a draft list of requisite communication elements through literature review and deliberation on monthly conference calls. A blinded iterative Delphi process was subsequently performed to generate a consensus list of requisite communication elements that participating experts agreed were necessary to safely and effectively assume the management of patients with diabetes upon care transitions.

Results: The Task Force completed a series of four iterative polls from September 2015 to August 2016, resulting in a final list of 22 requisite communication elements (the Diabetes Management Discharge Communication List), with the elements conceptually categorized into three domains: diagnosis and treatment, factors affecting glycemic control or patient risk, and patient self-management.

Conclusions: The Diabetes Management Discharge Communication List provides an initial framework for the development of diabetesspecific resources to improve clinical communication between care settings.

Keywords: Care transitions; Diabetes; Discharge planning; Hypoglycemia; Communication; Medications; Medication reconciliation; Quality improvement; Delphi consensus

J. Yu

Oak Ridge Institute for Science and Education,

Office of Disease Prevention and Health Promotion, Office of the Assistant Secretary for Health, Office of the Secretary, U.S. Department of Health and Human Services, Rockville, MD, USA

\section{Key Summary Points}

\section{Why carry out this study?}

Patients receiving diabetes medications are at risk for harm during care transitions due to cross-setting communication challenges.

No specific list of requisite communication elements exists for comprehensive care transitions for diabetes management.

This study sought to create a comprehensive list of requisite communication elements for diabetes management during care transitions.

\section{What was learned from this study?}

Using blinded, iterative, Delphi consensus methods, a subject matter expert task force was convened to develop a list of requisite diabetes management discharge communication (DMDC) elements that should be communicated to subsequent providers during care transitions.

Healthcare providers can use this list to create a comprehensive, consolidated diabetes management transition summary.

\section{INTRODUCTION}

Adverse drug events are frequent causes of emergency department visits and hospitalizations, and the majority of the most serious adverse drug events are considered to be preventable [1-4]. Incomplete or inaccurate communication of pertinent clinical information between care settings and clinicians has been identified as a contributor to preventable adverse drug events [3]. National efforts have been initiated to promote the interoperability of electronic medical record systems-to improve communication between care settings-and to 
provide medication therapy management services to patients with multiple comorbidities and polypharmacy $[5,6]$. Accreditation organizations have also implemented standards for medication reconciliation, and various groups have developed processes to guide effective care transitions and medication reconciliation efforts across broad patient populations [7-12]. Despite these efforts, adverse drug events continue to be unacceptably common, particularly across a very narrow list of high-risk drug classes (antihyperglycemic agents, anticoagulants, and antibiotics), which accounted for $60 \%$ of adverse drug event-related emergency department visits among older adults in 2013-2014 [2].

Antihyperglycemic agents are major contributors to serious adverse drug events, and care transitions for patients with diabetes have been identified as challenging because of regimen complexity, frequent changes in clinical status, multiple comorbidities, and suboptimal communication between care settings $[2,13,14]$. Furthermore, in older adults, geriatric syndromes such as cognitive dysfunction may interfere with diabetes self-management and increase the risk of errors and hypoglycemia in the older population [15]. Difficulties in transitions of care put patients at risk for unplanned care encounters, and antihyperglycemia agent-related emergency department visits result in hospitalization up to about half of the time $[2,16]$. Unfortunately, there is little guidance specific to care transitions involving patients with diabetes [17]. The growing number of available diabetes agents and the impact of other medical conditions and dietary factors on glycemic control make diabetes regimens remarkably complex. Insulin and other antihyperglycemic agents, such as glipizide, glyburide, and glimepiride, have been found among the top 15 drugs contributing to emergency department visits and hospitalizations due to hypoglycemic events in the elderly, and these events now outpace those for hyperglycemia $[2,18]$. While newer diabetes medications with low hypoglycemia risk are more commonly prescribed than sulfonylureas, increased utilization of insulin may be contributing to sustained national rates of hypoglycemic events
[19]. In 2013, the rates of severe hypoglycemia events for patients with type 2 diabetes on at least one antihyperglycemic agent were 1.3 per 100 person-years for ages $65-74$ years and 2.3 per 100 person-years for ages 75 years or older [19]. From January 1, 2007 through December 31, 2011, patients aged 80 years or older treated with insulin were twice as likely to visit the emergency department and five times as likely to be hospitalized compared to younger patients aged 45-64 years [13]. Current clinical practice recommendations advocate the preferential use of insulin for glycemic control during hospitalization and the temporary suspension of non-insulin therapy during the hospital stay [20]. Consequently, patients may experience changes in their diabetes regimens during hospitalization, and failure by care teams to perform medication reconciliation during transitions of care may increase the risk of adverse drug events [21].

Therefore, there is a need to streamline the transition of care process by improving the quality and consistency of communication between settings. The Centers for Medicare \& Medicaid Services (CMS), through the 11th Statement of Work, required its contracted Quality Innovation Network-Quality Improvement Organizations (QIN-QIOs) to undertake efforts to measurably reduce rates of adverse drug events for the three drug class priorities (antihyperglycemic agents, anticoagulants, and opioids) identified in the Department of Health and Human Services' 2014 National Action Plan for Adverse Drug Event Prevention [22]. In response, the Island Peer Review Organization (IPRO), the QIN-QIO contractor for the state of New York, and the drug safety task leaders from its affiliated contractors in South Carolina and the District of Columbia convened the IPRO Hypoglycemia Coalition to guide the development and implementation of effective intervention strategies. The Coalition identified care transitions for patients with diabetes as a domain requiring more focused resources and proceeded to develop a consensus list of requisite communication elements that participating experts agreed should be communicated between care settings during transitions of patients who are prescribed antihyperglycemic 
agents. The Diabetes Management Discharge Communication (DMDC) List is intended to serve as a framework for the development of more effective clinical tools and impactful quality measures and standards to reduce adverse drug events associated with antihyperglycemic agents.

\section{METHODS}

The IPRO Hypoglycemia Coalition, convened in February 2015 by IPRO, consisted of more than 40 voluntary members from across the USA with backgrounds in clinical practice, academia, the pharmaceutical industry, government, and/ or advocacy organizations. Some of the experts were identified through peer-reviewed publications on diabetes management and invited to participate. All of the Coalition members had an interest in improving the quality of diabetes management. Through routine deliberations on monthly conference calls, the Coalition identified suboptimal care transitions as a barrier to improving the quality and safety of diabetes care. Subsequently, a smaller Task Force comprising volunteers from the Coalition was charged with generating a list of requisite communication elements considered to be the minimum necessary for "downstream" practitioners to safely and effectively manage the diabetes regimens of patients transferred to their care from a previous ("upstream") setting. The list of requisite communication elements was intended to be applicable to transitions between any care settings in any order (e.g., hospital to skilled nursing, and vice versa) and to the full array of available antihyperglycemic agents.

Since there was no high-quality evidence (e.g., randomized controlled trials) as to what constituted the optimal requisite communication elements, the Task Force decided to utilize a formal Delphi process to generate consensus among its members in a controlled and structured manner. The Delphi method is an established and widely utilized approach to achieving group consensus and generating expert recommendations when the quantity or quality of available data sources on a topic are insufficient to make more robust evidencebased decisions [23]. This method has been applied to clinical topics such as patient safety incident reporting and anticoagulant safety during care transitions [24, 25]. A previous study using Delphi methodology generated a list of policy priorities in diabetes care that included the need for "increased cooperation and communication among health professionals, especially between hospitals and general practice" [26]. This was a quality improvement project performed within the CMS-funded QINQIO statement of work which did not involve human subjects research or require an ethics committee approval. All participants were aware of the objectives of the study, that the study would be published in a peer-reviewed journal, and provided consent to participate along with disclosures for any conflict of interest to verify independence. Consensus was achieved through blinded electronic polling and respondents' data was stored on passwordprotected server dedicated for sensitive data storage.

\section{Task Force Composition}

The Task Force consisted of 18 experts from Eastern USA (Connecticut, Florida, Georgia, Illinois, Maryland, Massachusetts, New York State, South Carolina, and Washington, D.C.). The members included six physicians, 10 pharmacists, and two registered nurses. The physicians were clinician-researchers at academic institutions who had published extensively in peer-reviewed journals on topics related to diabetes management, quality improvement, and/ or patient safety. In total, they had published more than 130 peer-reviewed articles at the time of the consensus process. Among the physicians, three were American Board of Internal Medicine-certified in both endocrinology, diabetes \& metabolism and geriatric medicine. Each of the pharmacists had more than 10 years of clinical experience with special interests in diabetes, quality improvement, and patient safety, and among them, six had a doctorate in pharmacy. The two registered nurses were trained as certified diabetes educators, and each 
had more than 20 years of experience working in inpatient and community settings, including caring for patients with diabetes.

\section{Formulation of Draft List of Requisite Communication Elements and Gap Analysis}

From February through September 2015, the Task Force compiled a draft list of requisite communication elements through literature review and deliberation on monthly conference calls. This effort generated a preliminary set of 32 requisite communication elements. To determine if these initial elements were relevant, practical, and reflective of the needs of clinical practice, a gap analysis was performed at one long-term care facility in New York State. An IPRO pharmacist reviewed the charts of 10 long-term care facility patients with diabetes who had recently been discharged from a hospital to determine whether the hospital communication to the long-term care facility included elements on the draft list. Nursing staff at the long-term care facility were provided the opportunity to suggest additional elements to add to the draft requisite communication elements. A summary report of the chart reviews was provided to the Task Force for review.

\section{Consensus Process}

A total of four iterative polls were conducted from September 2015 through August 2016. Task Force participants were provided the draft list of requisite communication elements prior to each polling period and were invited to suggest additional elements for consideration. The list of requisite communication elements was formally evaluated through blinded electronic polling (Survey Monkey ${ }^{\circledR}$, San Mateo, CA). Each participating Task Force member evaluated each communication element according to a 5-point Likert scale (strongly agree, agree, neutral, disagree, strongly disagree). Each element was paired with a brief "Expanded Guidance" section that elaborated upon the intent of the element. Task Force participation in the electronic polling was not mandatory but strongly encouraged. A minimum of nine participants including at least two physicians was required for each of the iterative polls. The scores and comments from each survey iteration were anonymized and shared with the Task Force members prior to the subsequent conference calls.

Consensus was considered to be achieved when an individual element received $80 \%$ or greater positive responses (strongly agree or agree) from the responding Task Force members, and these approved elements were removed from subsequent polls. Elements that did not achieve consensus upon a single iteration were deliberated upon further by the Task Force. These elements were either modified or combined with other outstanding elements and included in the subsequent poll or dropped. Approved or dropped elements could be reopened for discussion and consideration if three or more members made a request. All aspects of the consensus definition were defined a priori.

\section{RESULTS}

A quality improvement gap analysis of the current state regarding diabetes management discharge communication compared to the preliminary list of requisite communication elements occurred at one long-term care facility in New York State in June 2015. The gap analysis confirmed that the preliminary list of requisite communication elements was relevant to diabetes care and provided recommendations for additional elements such as communication about insulin sliding scales and diet.

The Task Force completed a series of four iterative polls from September 2015 to August 2016, resulting in a final list of 22 requisite communication elements, the DMDC List. The elements were organized conceptually into three domains: diagnosis and treatment (Table 1), factors affecting glycemic control or patient risk (Table 2), and patient self-management (Table 3). Task Force member participation in each of the iterative polls ranged from $70 \%$ to $80 \%$. The percentage agreement of panel members for each element was at least $80 \%$ at the time that each element was approved. All 
Table 1 Requisite communication elements: diagnosis and treatment

\begin{tabular}{ll}
\hline $\begin{array}{l}\text { Element } \\
\text { number }\end{array}$ & Requisite communication element \\
\hline 1 & Diabetes diagnosis, including subtype classification
\end{tabular}

Expanded guidance

Diabetes diagnosis, including subtype classification

2

Duration of diabetes (new diagnosis or chronic)

3

4

Target range for blood glucose next blood glucose test is due
The diagnosis of diabetes and the subclassifications

(type 1, type 2, gestational, iatrogenic, due to pancreatitis or pancreatic obstruction, other) should be clearly indicated as a medical condition for subsequent care professionals, regardless of whether it is a primary purpose for receiving services from the index ("upstream") setting. The diagnosis is NOT to be deduced by evaluation of drug regimen or prescribed diet

Subsequent settings should be provided some characterization of the duration of the diabetes diagnosis and/or treatment. Newly diagnosed patients may be more unstable, and hypoglycemia risk has been shown to increase with duration of diabetes. Patients with a long-standing diagnosis of diabetes will likewise be at greater risk of microvascular and macrovascular complications than those without. Such characterizations need not be exact. Terms such as "recently diagnosed" and "diabetic for $5+$ years" are acceptable, although more detailed and precise information is preferred, such as date of diagnosis (month/year) obtained from patient medical record

Recent blood glucose values along with blood glucose monitoring schedule with date and time when the

Subsequent settings should receive all blood glucose values recorded by the referring health setting in the preceding 7 days, with values over a greater monitoring period preferred. In instances in which the patient duration of stay in the "upstream" setting is less than 7 days, all values recorded in that setting should be provided to subsequent care settings

Subsequent care settings should receive details (i.e., numeric boundaries) of the blood glucose range targeted for the individual patient while under the care of the referring ("upstream”) setting 
Table 1 continued

\begin{tabular}{|c|c|c|}
\hline $\begin{array}{l}\text { Element } \\
\text { number }\end{array}$ & Requisite communication element & Expanded guidance \\
\hline 5 & History of hypoglycemic episodes & $\begin{array}{l}\text { Subsequent care settings should receive a history of } \\
\text { hypoglycemia episodes occurring within the last } \\
7 \text { days, including date and time of event, whether } \\
\text { loss of consciousness occurred, a list of then- } \\
\text { current drugs, and an explanation for the } \\
\text { hypoglycemic event }\end{array}$ \\
\hline 6 & Current antihyperglycemic drug regimen & $\begin{array}{l}\text { Subsequent care settings should receive detailed } \\
\text { characterizations of all antihyperglycemic drugs at } \\
\text { the time of transition between care settings, } \\
\text { including drug names, dosages, routes, and } \\
\text { frequencies. The presence of an insulin pump } \\
\text { should be communicated with pump settings. } \\
\text { Communication should also include date and time } \\
\text { of last doses given AND date and times that next } \\
\text { scheduled doses are due }\end{array}$ \\
\hline 7 & $\begin{array}{l}\text { Recent changes in the antihyperglycemic drug } \\
\text { regimen }\end{array}$ & $\begin{array}{l}\text { In addition to the current active antihyperglycemic } \\
\text { drug regimen, subsequent care settings should } \\
\text { receive details of all recent (at least in the past } \\
7 \text { days) changes in antihyperglycemic drugs. } \\
\text { Documentation should include all newly } \\
\text { introduced agents, dose increases, decreases, } \\
\text { discontinuations, or "holds," and provide detailed } \\
\text { justification for such changes (e.g., hyperglycemic } \\
\text { or hypoglycemic events, infection). If the duration } \\
\text { of care in the "upstream” setting was less than } \\
7 \text { days, details of all regimen changes for the full } \\
\text { length of care in that setting should be } \\
\text { communicated. Rationale for changes between the } \\
\text { pre-admission medication list and the discharge } \\
\text { medication list should be documented }\end{array}$ \\
\hline
\end{tabular}


Table 1 continued

\begin{tabular}{|c|c|c|}
\hline $\begin{array}{l}\text { Element } \\
\text { number }\end{array}$ & Requisite communication element & Expanded guidance \\
\hline 8 & $\begin{array}{l}\text { Identification of and rationale for sliding scale insulin } \\
\text { order initiated during hospitalization }\end{array}$ & $\begin{array}{l}\text { Long-term use of sliding scale orders should be } \\
\text { avoided, and insulin orders should be standardized } \\
\text { post-discharge. When fluctuating needs for insulin } \\
\text { are required, a sliding scale should be used } \\
\text { cautiously and judiciously to avoid hyper- or } \\
\text { hypoglycemic events, and the scale should be } \\
\text { documented. Special attention to patient education } \\
\text { on use of a sliding scale may be warranted (the } \\
\text { patient should learn to differentiate between long- } \\
\text { acting and rapidly acting insulin, the patient must } \\
\text { know when to self-monitor blood glucose and } \\
\text { when to inject the insulin, etc.) }\end{array}$ \\
\hline 9 & $\begin{array}{l}\text { Current diet including whether it is administered via } \\
\text { enteral feeding tube and, if so, the schedule should } \\
\text { be provided }\end{array}$ & $\begin{array}{l}\text { Subsequent professionals should be informed of the } \\
\text { patient's current recommended diet (e.g., total } \\
\text { calories, composition) and, if the patient was in } \\
\text { control of food decisions, a characterization of } \\
\text { patient adherence to the recommended diet should } \\
\text { also be communicated. If the diet is administered } \\
\text { via enteral feeding tube, the documentation should } \\
\text { indicate the type of tube (e.g., G-tube, G-J tube, } \\
\text { J-tube) and whether nutrition is administered as } \\
\text { bolus or continuous feeds }\end{array}$ \\
\hline
\end{tabular}

polling included at least nine panel members, two or more of whom were physicians.

Deliberations encompassed the consideration of newly proposed communication elements, the status of elements that were not approved in previous polling, and the possible modification or consolidation of outstanding elements. The explicit communication of falls risk was discussed at length but ultimately not approved because of the lack of an accepted "gold standard" falls risk assessment, the lack of specificity to diabetes, and the ability of downstream practitioners to perform gait assessments for their patients in real time. In addition, the explicit presence of neuropathy was discussed but not endorsed as a requisite element, as this too may be assessed objectively by recipient practitioners. Consideration was also given to the explicit communication of the presence or absence of specific conditions (e.g., infections, heart failure, thyroid disease); however, these elements did not achieve consensus. While explicit details regarding systemic corticosteroid therapy were approved as a requisite communication element, separate elements for other drugs that affect glycemic control (e.g., antipsychotics, beta adrenergic blockers, thiazide diuretics, protease inhibitors) were consolidated into a single element on nonantihyperglycemic agent drug regimen (Table 2, \#16). Explicit communication of hemoglobin A1c (HbA1c) initially achieved consensus in the first poll. However, after further deliberations, the Task Force felt strongly 
Table 2 Requisite communication elements: factors affecting glycemic stability or patient risk

\begin{tabular}{ll}
\hline $\begin{array}{l}\text { Element } \\
\text { number }\end{array}$ & $\begin{array}{l}\text { Requisite communication } \\
\text { element }\end{array}$ \\
\hline 10 & Age \\
& \\
11 & $\begin{array}{c}\text { Presence of surgical interventions } \\
\text { or trauma/tissue damage }\end{array}$ \\
12 & Presence of dementia
\end{tabular}

Expanded guidance

13 Presence of delirium if known

$14 \quad$ Last value and date of renal assessment

Current non-antihyperglycemic drug list
Patients at the extremes of age may be at greater risk of adverse events compared to others, have altered drug clearance (e.g., the very old), or have less ability to self-manage the disease (e.g., the very young), so patient age should be clearly communicated to all subsequent care settings

Clinical documentation should clearly characterize any recent instances of tissue damage, regardless of cause

Clinical diagnosis should clearly indicate if there was a pre-admission diagnosis of dementia

Clinical documentation should clearly characterize any recent (past 30 days) episodes of acute delirium, if information is available

Diabetes is known to advance declines in renal function (i.e., microvascular disease), and renal dysfunction due to any cause may affect drug dosing and contraindications (e.g., metformin). Subsequent care settings should receive a recent, objective assessment of patient renal function when patients transition from one care setting to another. (i.e., most recent assessment performed at the referring care setting). The assessment should state the method used (e.g., eGFR, Cockroft-Gault or MDRD equation), the date, and the numeric result. The assessment should be dated within the last year

Medications unrelated to antihyperglycemic treatment may contribute to hyperglycemia, hypoglycemia, and hypoglycemia unawareness (e.g., beta blockers). Subsequent care settings should be provided comprehensive lists of all current medications so they can evaluate the possible impact of such medications on the patient's diabetes care plan

If glucocorticoids are utilized, clinical documentation should clearly characterize the status of any systemic regimen. Active indications for glucocorticoid therapy must be provided as well as details of the regimen, including temporal factors (acute vs. chronic use, when initiated, etc.), dose trajectory (escalating, deescalating, or stable), and the current drug, dose, route, and frequency. Details should include when last dose was given and when next dose is due. Specific dose tapers and/or dose escalation schedule should be provided (e.g., details of the remaining portion of the taper). The absence of corticosteroids from a comprehensive active medication regimen is sufficient to denote absence of systemic corticosteroid use

eGFR estimated glomerular filtration rate, MDRD Modification of Diet in Renal Disease 
Table 3 Requisite communication elements: patient self-management

\begin{tabular}{ll}
\hline $\begin{array}{l}\text { Element } \\
\text { number }\end{array}$ & Requisite communication element \\
\hline 17 & $\begin{array}{c}\text { Assessment of patient ability to self-administer } \\
\text { current diabetes regimen }\end{array}$ \\
\end{tabular}

Expanded guidance

Clinical documentation characterizing in some manner (objectively or in subjective narrative) patient ability to measure and administer all agents prescribed for blood glucose management, including an objective or subjective characterization of patient visual acuity. Should also assess whether patient has previously received diabetes self-management education (within the last 6 months or at recent change in regimen)

If self-monitoring is utilized, clinical documentation characterizing patient ability to objectively monitor blood glucose (i.e., can appropriately manipulate the device), record and communicate results to healthcare professionals as necessary

Clinical documentation characterizing patient ability to recognize symptoms of hyper- and hypoglycemia and to take appropriate responsive actions (e.g., glucose gel administration). Specific characterization of the presence or absence of hypoglycemia unawareness (symptom types, blood glucose thresholds) is preferred

Patient education is a key component of quality diabetes management, particularly as patients transition between care settings and experience changes in medical status, diet, and medications. Documentation of the provision of educational materials should be shared with subsequent care settings. Details of the content of such materials are recommended, but not required

When education is provided, clinical documentation should characterize patient comprehension of their diabetes-related care plan, including recommended diet, monitoring and symptom recognition, medication administration and adherence, and communication with healthcare professionals

An appointment for subsequent follow-up should be scheduled within 7 days of discharge and documented in the appropriate system 
that HbA1c should not be included as a requisite communication element, as recent guidelines on the management of diabetes in longterm care facilities advised clinicians to avoid relying on HbA1c since it may be misleading in this patient population [27]. In addition, including $\mathrm{HbA} 1 \mathrm{c}$ as a requisite communication element may inadvertently lead inpatient clinicians to order this test and initiate treatment, which could result in overtreatment and potential harm.

\section{DISCUSSION}

The DMDC List introduces the concept of a standardized minimum set of requisite communication elements to be communicated between settings during care transitions of patients with diabetes. This list can be used regardless of the settings involved, the direction of care (increasing or decreasing level of acuity), or whether diabetes is a primary or secondary medical issue in the care transition. The adoption of such an approach has the potential to drive a cultural change in which patients with diabetes cannot be transferred to a different care setting without the most current and relevant clinical information to manage their care in the near term.

This concept stems from the results of a care transitions pilot study conducted by IPRO, which found that basic clinical information elements were routinely lacking from care transition documents shared within a sample of hospitals, long-term care facilities, and home care agencies for patients receiving anticoagulants, another high-risk drug class. In that pilot study, upstream practitioners failed to effectively communicate the 17 key elements approximately $50 \%$ of the time, potentially putting patients at significant risk for avoidable adverse drug events [28].

Structured discharge templates serve as an important tool in improving the quality of discharge documentation and communication between settings. One study found that the use of a discharge summary template improved the quality of the summary as well as significantly decreased the length of dictation time [29].
Another study revealed that both quality and timeliness of the discharge summary improved with the use of a template, and certain elements such as follow-up issues and pending test results were found more often in the discharge summary [30]. Few studies have examined the role of structured discharge summaries for patients with high-risk medical conditions such as diabetes $[17,31]$. In addition, studies on the communication and documentation of essential information during discharge are consistently lacking in the literature [17, 32-34]. Kripalani et al. reported in 2007 that direct communication between care settings occurred infrequently and discharge summaries often lacked details on diagnostic test results, treatment or hospital course, discharge medications, pending test results, patient counselling, and follow-up plans [35]. These deficits in communication and documentation could lead to serious implications for patient care. Therefore, the 2020 issue of "Standards of Medical Care in Diabetes" from the American Diabetes Association offers specific recommendations on items that should be included in discharge documentation [20]. These include descriptions of recent episodes of hypoglycemia, documentation of medication changes, characterization of patient ability to recognize and self-treat hypoglycemia, patient level of understanding regarding diabetes management, and scheduling of outpatient followup. The DMDC List includes the specific recommendations of the American Diabetes Association.

Care models that have demonstrated reductions in preventable re-hospitalizations and adverse drug events have often accomplished this through resource-intensive efforts involving dedicated clinical specialists, coaches, and lay navigators $[8,36,37]$. More widespread and sustainable improvements in patient care will likely require enhanced information sharing and clinical decision support features made possible through optimized, interoperable electronic health records [38]. The DMDC List provides an initial framework for development, testing, and refinement of resources that focus exclusively on care transitions involving patients treated for diabetes. Such resources may include discharge summary templates, 
patient intake checklists, quality assurance metrics, and others. The creation of well-formatted electronic discharge summaries reflecting the DMDC List elements will require additional effort, as each will need to be translated or cross-walked to corresponding clinical database fields and codes. However, the Task Force believes that creation of the DMDC List is an important developmental step toward the creation of diabetes-specific resources targeting care transitions.

The DMDC List was developed with contributions from a multidisciplinary panel of experienced diabetes clinicians, and formal consensus was achieved through the application of a blinded iterative Delphi process with a high a priori threshold. One limitation of the DMDC List is that the associations between the individual requisite communication elements and adverse drug events are not currently known. Prospective studies that evaluate the communication of these requisite communication elements and their impact on rates of adverse drug events are needed to confirm the value of the DMDC List. Another limitation is that the Task Force Consensus panel did not include patients with diabetes, caregivers, or other stakeholders (e.g., hospital and long-term care facility administrators). Their opinions about transitions of care are important and should be considered for inclusion in future research. The DMDC list is noted to be extensive and the gathering and consolidation of this information into a discharge summary may be difficult because of current electronic health record limitations. The comprehensive DMDC list is meant to reflect an ideal discharge communication to the subsequent provider during care transitions. The expectation is that the provider can prioritize and communicate the elements that they feel are most important to their practice and the receiving clinician.

\section{Applications and Next Steps}

The DMDC List may have immediate value in the development of standardized criteria to improve discharge communication for all patients with diabetes. In addition, the DMDC
List is not specific to the USA and can be utilized in healthcare systems across the world. Future efforts should focus on the validation of the DMDC List elements through clinical studies. Lists of criteria such as the DMDC List are adaptable and can be easily integrated into hospital practice. Furthermore, the DMDC List may be incorporated into the curriculum for medical and allied health professional trainees as a guide to improving communication during transitions of care for patients with diabetes.

\section{CONCLUSIONS}

The Care Transitions Task Force of the IPRO Hypoglycemia Coalition utilized a Delphi process to identify 22 requisite communication elements that the multidisciplinary group agreed should be consistently and reliably communicated between clinical professionals when patients treated for diabetes transition between care settings. The DMDC List may have utility in the creation of new clinical tools and enhancements to electronic medical record systems.

\section{ACKNOWLEDGEMENTS}

The authors acknowledge and appreciate the contributions of these additional consenting experts to the Task Force and/or manuscript critique: Cheryl A Anderson, BS, RPh, The Carolinas Center for Medical Excellence, Cary, NC; Lisa Anzisi, PharmD, MS, BCPS, NYULH Network Integration, NY, NY; Marie Frazzitta, DNP, FNP-c, MBA, ADCES, Abbott Diabetes Care, NY, NY; Andrew Geller, MD, Division of Healthcare Quality Promotion, Centers for Disease Control and Promotion, Atlanta, GA; Ann Marie Hasse, MSN, RN, CDCES, HWNC-BC, Long Island Jewish Medical Center, New Hyde Park, NY; Mary Jo Lakomski, BSPharm, CDCES, BCACP, Upstate University Hospital, Syracuse, NY; Mark McConnell, M.D., Department of Veterans Affairs, Iron Mountain, MI; Gurdeep S. Sareen, PharmD, MPH, CareMount (part of Optum), Mount Kisco, NY; Robin Stevens, MSN, RNC-OB, C-EFM, CDCES, HealthAlliance of the 
Hudson Valley, Kingston, NY; Jennifer Thomas, PharmD, Qlarant, District of Columbia; Alexandra Watson, PharmD, BCACP, Community Care Physicians, P.C. and Albany College of Pharmacy and Health Sciences, Albany, NY; Patricia Weil, MSN, ANP-BC, CDCES, Plainview Hospital, Northwell Health, Plainview, NY.

Funding. The authors disclose receipt of the following financial support for the research, authorship, and/or publication of this article: The consensus statement was produced by the IPRO Hypoglycemia Coalition, which was assembled and supported by Island Peer Review Organization (IPRO), the Centers for Medicare \& Medicaid Services (CMS)-designated Quality Innovation Network-Quality Improvement Organization (QIN-QIO) for New York State and lead for the IPRO Quality Innovation Network (AQIN) under the 10th and 11th Statements of Work. The analyses upon which this publication is based were performed under Contract Number HHSM-500-2014-QIN013I, funded by the Centers for Medicare \& Medicaid Services, an agency of the United States Department of Health and Human Services. The content of this publication does not necessarily reflect the views or policies of CMS or the Department of Health and Human Services, nor does mention of trade names, commercial products, or organizations imply endorsement by the United States Government. The authors assume full responsibility for the accuracy and completeness of the ideas presented. The Rapid Service Fee was funded by IPRO.

Authorship. All named authors meet the International Committee of Medical Journal Editors (ICMJE) criteria for authorship for this article, take responsibility for the integrity of the work as a whole, and have given their approval for this version to be published.

Author Contributions. All authors accept responsibility for all aspects of the work. Conception and Design: Medha N. Munshi, Hermes J. Florez, Elbert S. Huang, Kasia J. Lipska, Willy Marcos Valencia, Darren M. Triller. Funding acquisition: Anne Myrka. Drafting and revising the manuscript: Medha N. Munshi, Sarah L. Sy,
Hermes J. Florez, Elbert S. Huang, Kasia J. Lipska, Anne Myrka, Willy Marcos Valencia, Joyce $\mathrm{Yu}$, Darren M. Triller. Final approval of the version: All authors.

Disclosures. Medha N. Munshi is a consultant for Sanofi and Lilly. Kasia J. Lipska receives support from the Centers for Medicare \& Medicaid Services to develop and evaluate publicly reported quality measures. Joyce Yu contributed to this work when completing a fellowship for the Oak Ridge Institute for Science and Education in the U.S. Department of Health and Human Services and is now employed by the Food and Drug Administration, Silver Spring, Maryland, USA. The contributions by Joyce Yu represent the author's own opinions and do not reflect the view of the Food and Drug Administration, the Department of Health and Human Services, or the United States government. Sarah L. Sy, Hermes J. Florez, Elbert S. Huang, Willy Marcos Valencia and Anne Myrka do not have any conflicts of interest to declare. Hermes J. Florez and Willy Marcos Valencia are now also affiliated with the Medical University of South Carolina, Departments of Public Health Sciences, Department of Medicine/Division of Endocrinology, and Institute for Healthy Aging, Charleston, South Carolina, USA. Darren M. Triller was a medication safety pharmacist employed by IPRO when this work was conducted and is now employed by the Anticoagulation Forum, Newton, Massachusetts, USA.

Compliance with Ethics Guidelines. This was a quality improvement project performed within the CMS-funded QIN-QIO statement of work which did not involve human subjects research or require an ethics committee approval. All participants were aware of the objectives of the study, that the study would be published in a peer-reviewed journal, and provided consent to participate along with disclosures for any conflict of interest to verify independence. Consensus was achieved through blinded electronic polling and respondents' data was stored on password-protected server dedicated for sensitive data storage. 
Data Availability. The datasets generated during and/or analyzed during the current study are available from the corresponding author on reasonable request.

Open Access. This article is licensed under a Creative Commons Attribution-NonCommercial 4.0 International License, which permits any non-commercial use, sharing, adaptation, distribution and reproduction in any medium or format, as long as you give appropriate credit to the original author(s) and the source, provide a link to the Creative Commons licence, and indicate if changes were made. The images or other third party material in this article are included in the article's Creative Commons licence, unless indicated otherwise in a credit line to the material. If material is not included in the article's Creative Commons licence and your intended use is not permitted by statutory regulation or exceeds the permitted use, you will need to obtain permission directly from the copyright holder. To view a copy of this licence, visit http:// creativecommons.org/licenses/by-nc/4.0/.

\section{REFERENCES}

1. Budnitz DS, Lovegrove MC, Shehab N, Richards CL. Emergency hospitalizations for adverse drug events in older Americans. N Engl J Med. 2011;365(21): 2002-12.

2. Shehab N, Lovegrove MC, Geller AI, Rose $\mathrm{KO}$, Weidle NJ, Budnitz DS. US emergency department visits for outpatient adverse drug events, 2013-2014. JAMA. 2016;316(20):2115-25.

3. Gurwitz JH, Field TS, Harrold LR, et al. Incidence and preventability of adverse drug events among older persons in the ambulatory setting. JAMA. 2003;289(9):1107-16.

4. Field TS, Gurwitz JH, Harrold LR, et al. Strategies for detecting adverse drug events among older persons in the ambulatory setting. J Am Med Inform Assoc. 2004;11(6):492-8.

5. Patient-centered medical home (PCMH) recognition. National Committee for Quality Assurance (NCQA). http://www.ncqa.org/programs/ recognition/practices/patient-centered-medicalhome-pcmh. Accessed 18 Aug 2017.
6. Centers for Medicare \& Medicaid Services. Medication Therapy Management programs for complex health needs. https://www.medicare.gov/part-d/ coverage/medication-therapy-management/ medication-therapy-programs.html. Accessed 4 Oct 2017.

7. National Patient Safety Goals Effective January 2017. https://www.jointcommission.org/assets/1/6/ NPSG_Chapter_HAP_Jan2017.pdf. Accessed 8 Aug 2017.

8. Coleman EA, Parry C, Chalmers S, Min SJ. The care transitions intervention: results of a randomized controlled trial. Arch Intern Med. 2006;166(17): $1822-8$

9. Bixby MB, Naylor MD. The Transitional Care Model (TCM): hospital discharge screening criteria for high-risk older adults. Medsurg Nurs. 2010;19(1): 62-3.

10. Adams CJ, Stephens K, Whiteman K, Kersteen H, Katruska J. Implementation of the Re-Engineered Discharge (RED) toolkit to decrease all-cause readmission rates at a rural community hospital. Qual Manag Health Care. 2014;23(3):169-77.

11. Salanitro AH, Kripalani S, Resnic J, et al. Rationale and design of the Multicenter Medication Reconciliation Quality Improvement Study (MARQUIS). BMC Health Serv Res. 2013;13:230.

12. Gleason KM, McDaniel MR, Feinglass $\mathrm{J}$, et al. Results of the Medications at Transitions and Clinical Handoffs (MATCH) study: an analysis of medication reconciliation errors and risk factors at hospital admission. J Gen Intern Med. 2010;25(5): 441-7.

13. Geller AI, Shehab N, Lovegrove MC, et al. National estimates of insulin-related hypoglycemia and errors leading to emergency department visits and hospitalizations. JAMA Intern Med. 2014;174(5): 678-86.

14. Black RL, Duval C. Diabetes discharge planning and transitions of care: a focused review. Curr Diabetes Rev. 2019;15(2):111-7.

15. Munshi MN. Cognitive dysfunction in older adults with diabetes: what a clinician needs to know. Diabetes Care. 2017;40(4):461-7.

16. LaManna JB, Bushy A, Norris AE, Chase SK. Early and intermediate hospital-to-home transition outcomes of older adults diagnosed with diabetes. Diabetes Educ. 2016;42(1):72-86.

17. Doyle MA, Malcolm JC, Liu D, Maranger J, Ooi TC, Keely E. Using a structured discharge letter template to improve communication during the transition 
from a specialized outpatient diabetes clinic to a primary care physician. Can J Diabetes. 2015;39(6): 457-66.

18. Lipska KJ, Ross JS, Wang Y, et al. National trends in US hospital admissions for hyperglycemia and hypoglycemia among Medicare beneficiaries, 1999 to 2011. JAMA Intern Med. 2014;174(7):1116-24.

19. Lipska KJ, Yao X, Herrin J, et al. Trends in drug utilization, glycemic control, and rates of severe hypoglycemia, 2006-2013. Diabetes Care. 2017;40(4):468-75.

20. American Diabetes Association. Diabetes Care in the Hospital: Standards of Medical Care in Diabetes2020. Diabetes Care. 2020;43(Suppl 1):S193-202.

21. Donihi AC. Practical recommendations for transitioning patients with type 2 diabetes from hospital to home. Curr Diab Rep. 2017;17(7):52.

22. National Action Plan for Adverse Drug Event Prevention. Washington, DC: U.S. Department of Health and Human Services, Office of Disease Prevention and Health Promotion; 2014.

23. Diamond IR, Grant RC, Feldman BM, Pencharz PB, Ling SC, Moore AM. Defining consensus: a systematic review recommends methodologic criteria for reporting of Delphi studies. J Clin Epidemiol. 2014;67(4):401-9.

24. Howell AM, Burns EM, Hull L, Mayer E, Sevdalis N, Darzi A. International recommendations for national patient safety incident reporting systems: an expert Delphi consensus-building process. BMJ Qual Saf. 2017;26(2):150-63.

25. Triller D, Myrka A, Gassler J, et al. Defining minimum necessary anticoagulation-related communication at discharge: consensus of the care transitions task force of the New York state anticoagulation coalition. Jt Comm J Qual Patient Saf. 2018;44(11):630-40.

26. Gallagher M, Bradshaw C, Nattress H. Policy priorities in diabetes care: a Delphi study. Qual Health Care. 1996;5(1):3-8.

27. Munshi MN, Florez H, Huang ES, et al. Management of Diabetes in long-term care and skilled nursing facilities: a position statement of the American Diabetes Association. Diabetes Care. 2016;39(2):308-18.

28. Myrka A. Improving medication reconciliation and anticoagulation management across care settings. 26th Annual National Forum on Quality
Improvement in Health Care; December 8, 2014; Orlando, FL.

29. Rao P, Andrei A, Fried A, Gonzalez D, Shine D. Assessing quality and efficiency of discharge summaries. Am J Med Qual. 2005;20(6):337-43.

30. O'Leary KJ, Liebovitz DM, Feinglass J, et al. Creating a better discharge summary: improvement in quality and timeliness using an electronic discharge summary. J Hosp Med. 2009;4(4):219-25.

31. Liesenfeld B, Heekeren H, Schade G, Hepp KD. Quality of documentation in medical reports of diabetic patients. Int J Qual Health Care. 1996;8(6): 537-42.

32. Hall W, Keane P, Wang S, Debell F, Allana A, Karia $P$. Intensive care discharges: improving the quality of clinical handover through changes to discharge documentation. BMJ Qual Improv Rep. 2015;4(1): u209711.w4036.

33. Axon RN, Penney FT, Kyle TR, et al. A hospital discharge summary quality improvement program featuring individual and team-based feedback and academic detailing. Am J Med Sci. 2014;347(6): 472-7.

34. Dean SM, Gilmore-Bykovskyi A, Buchanan J, Ehlenfeldt B, Kind AJ. Design and hospital-wide implementation of a standardized discharge summary in an electronic health record. Jt Comm J Qual Patient Saf. 2016;42(12):555-AP511.

35. Kripalani S, LeFevre F, Phillips CO, Williams MV, Basaviah P, Baker DW. Deficits in communication and information transfer between hospital-based and primary care physicians: implications for patient safety and continuity of care. JAMA. 2007;297(8):831-41.

36. Schnipper JL, Kirwin JL, Cotugno MC, et al. Role of pharmacist counseling in preventing adverse drug events after hospitalization. Arch Intern Med. 2006;166(5):565-71.

37. Jack BW, Chetty VK, Anthony D, et al. A reengineered hospital discharge program to decrease rehospitalization: a randomized trial. Ann Intern Med. 2009;150(3):178-87.

38. Anthony D, Chetty VK, Kartha A, McKenna K, DePaoli MR, Jack B. Re-engineering the hospital discharge: an example of a multifaceted process evaluation. In: Henriksen K, Battles JB, Marks ES, Lewin DI, editors. Advances in patient safety: from research to implementation (volume 2: concepts and methodology). Rockville (MD): Agency for Healthcare Research and Quality (US); 2005. 